\title{
LLC: Critérios diagnósticos, imunofenotipagem e diagnóstico diferencial
} CLL: Diagnostic criteria, immunophenotyping and differential diagnosis

Irene Lorand-Metze

\begin{abstract}
O diagnóstico da LLC é baseado em dados do hemograma e da imunofenotipagem dos linfócitos periféricos: linfocitose acima de 5 (ou 10) $\times 10^{9} / \mathrm{L}$ com fenótipo CD19, CD5, CD23 e expressão fraca de imunoglobulinas de superfície monoclonais. A expressão de CD38 ocorre em cerca da metade dos casos e tem relação com o estado não mutado de Ig V. A biópsia de medula só deverá ser realizada antes do tratamento ou quando os dois exames acima não permitirem um diagnóstico definitivo. $O$ diagnóstico diferencial é com os outros linfomas $B$ indolentes, que freqüentemente apresentam células neoplásicas circulantes. Este diagnóstico diferencial é baseado na imunofenotipagem, biópsia de medula ou linfonodo. Rev. bras. hematol. hemoter. 2005;27(4):233-235.
\end{abstract}

Palavras-chave: Leucemia linfóide crônica; diagnóstico; imunofenotipagem; síndromes linfoproliferativas.

\section{Introdução}

Segundo a classificação OMS vigente, ${ }^{1}$ a LLC é uma neoplasia de linhagem $\mathrm{B}$, periférica. $\mathrm{O}$ diagnóstico é feito quando o paciente apresenta linfocitose persistente acima de $10 \times 10^{9} / \mathrm{L}$ e linfocitose $>40 \%$ no mielograma, independente da presença ou não de linfonodomegalia, hepato e/ou esplenomegalia, anemia e/ou plaquetopenia. Raramente pode se apresentar apenas como tumor nodal ou extranodal, sem infiltração medular e linfocitose periférica. O cut-off de $5 \mathrm{x}$ $10 / \mathrm{L}$ e linfocitose $>30 \%$ no mielograma também tem sido largamente usado. Esta discrepância é principalmente devida à ocorrência de linfocitose $\mathrm{B}$ monoclonal benigna ou de significado indeterminado (ver capítulo à frente). Em relação a este dado, a LLC também apresenta um contínuo de lesões clonais precoces, estáveis ou com regressão espontânea como é observado nas gamopatias monoclonais e na gastrite pelo H. pylori / linfoma MALT. Por isso, e pelo fato de que as LLC de estádio Binet A' (com linfocitose abaixo de $30 \times 10^{9} / \mathrm{L}$ ) não necessitam de tratamento, o cut-off usado não é um elemento essencial para o prognóstico do paciente. Na situação de linfocitoses clonais discretas, onde não encontramos organomegalias, o paciente deverá ser detalhadamente esclarecido sobre o potencial evolutivo desta linfocitose, bem como do impacto deste achado sobre o seu risco (já que pacientes com esta linfocitose têm sobrevida igual à da população geral sem linfocitose).

A morfologia das células neoplásicas é semelhante à de linfócitos normais. Porém, geralmente se encontra até $2 \%$ de pró-linfócitos ou blastos (células maiores com nucléolos e citoplasma mais amplos). Na forma atípica, os pró-linfócitos podem representar 10\%-55\%. É comum a ocorrência de restos celulares (manchas de Gumprecht). A presença de células linfóides clivadas sugere o diagnóstico de linfoma folicular. ${ }^{2}$ Por outro lado, células com morfologia de células linfoplasmocitárias indicam tratar-se de um linfoma linfoplasmocítico. ${ }^{3,4}$ Por esta razão, o diagnóstico de LLC depende da determinação do imunofenótipo dos linfócitos circulantes.

O estudo da medula óssea (citologia e histologia) só é necessário quando se trata de linfocitoses discretas, isoladas, sem quadro clínico inequívoco. A histologia de medula óssea também pode ajudar no diagnóstico diferencial com alguns outros linfomas indolentes leucemizados (Tabela 1). ${ }^{1}$

Departamento de Clínica Médica, Faculdade de Ciências Médicas, Universidade Estadual de Campinas.

Endereço para correspondência: Irene Lorand-Metze

Hemocentro - Unicamp

Rua Carlos Chagas, 480

Caixa Postal 6198

13081-970 - Campinas-SP

E-mail: ilmetze@unicamp.br 
Tabela 1

Diagnóstico diferencial da LLC

\begin{tabular}{|c|c|c|c|c|c|c|}
\hline & Morfologia & CD20 & CD5 & CD23 & slg & Outros macadores \\
\hline LLC & $<50 \%$ de pró-linfócitos & $\operatorname{dim}$ & + & + & $\operatorname{dim}$ & CD38+ \\
\hline L. pró-linfocítica & $>50 \%$ pró-linfócitos & $+/++$ & $+30 \%$ & _- & $+1-$ & CD79a+ \\
\hline L. cel.-manto & & ++ & + & - & ++ & $\begin{array}{c}\text { Ciclina D1 } \\
\mathrm{t}(11 ; 14)\end{array}$ \\
\hline L. linfoplasmocítico & $\begin{array}{c}\text { Cel. linfo- } \\
\text { Plasmocitóides } \\
\text { MO: infiltração intersticial, } \\
\text { vasos e fibrose }\end{array}$ & ++ & $+5-20 \%$ & $+1-$ & ++ & CD79b+CD38 +/- Clg + \\
\hline L folicular & Cel. clivadas & ++ & - & $+1-$ & ++ & CD10+bcl-2t(14;18) \\
\hline L esplênico & $\begin{array}{l}\text { MO: infiltração focal com centros } \\
\text { germinativos }\end{array}$ & ++ & - & - & + & CD79 a + \\
\hline Tricoleucemia & $\begin{array}{l}\text { MO: infiltração intersticial } \\
\text { com fibrose }\end{array}$ & ++ & - & - & + & $\begin{array}{c}\text { CD25, CD103, DBA44 } \\
\text { (histo), TRAP }\end{array}$ \\
\hline
\end{tabular}

TRAP: fosfatose ácida tartarato-resistente; MO: biópsia de medula

Tem-se atribuído aos achados da biópsia de medula óssea um valor prognóstico, já que uma infiltração focal (central paratrabecular é rara) ou intersticial indica menor massa tumoral. Mas este dado isolado tem valor reduzido quando comparado com os parâmetros prognósticos bioquímicos e moleculares, bem como o estadiamento. Num artigo de revisão da Clínica Mayo $^{5}$ se recomenda que o estudo da medula óssea só deve ser feito antes de se iniciar quimioterapia.

\section{Imunofenotipagem}

Juntamente com o quadro clínico e os dados do hemograma, a imunofenotipagem é a principal avaliação diagnóstica e permite o diagnóstico diferencial com as outras síndromes linfoproliferativas. ${ }^{1}$

O painel usado no citômetro de fluxo pode ser de duas ou de três cores. O que é importante, quando a linfocitose está abaixo de $30 \times 10^{9} / \mathrm{L}$, é que se adquira pelo menos 10.000 células (ou mais) no gate de linfócitos, para se ter uma análise confiável. É importante também que se lave o pellet de leucócitos antes de se agregarem os anticorpos anticadeias leves (ou pesadas) de imunoglobulinas. ${ }^{6}$

Os linfócitos da LLC expressam CD19, CD5, CD23 e, fracamente, imunoglobulinas de superfície com caráter clonal (só cadeia kappa ou só lambda). ${ }^{1}$ A expressão de CD79b e CD22 é fraca ou ausente. FMC7 sempre é negativo. Estes achados permitem fazer o diagnóstico diferencial com outros linfomas B leucemizados.

A expressão de CD38 é variável. Em 1999, Damle et $\mathrm{al}^{7}$ demonstraram que tanto a porcentagem de células CD38+ quanto a intensidade média de fluorescência da expressão deste antígeno tinham forte correlação inversa com a porcentagem de mutações do gene $\mathrm{V}\left(\mathrm{V}_{\mathrm{H}}\right.$ e $\left.\mathrm{V}_{\mathrm{L}}\right)$ das imunoglobulinas. De fato, havia dois grupos com expressão signi- ficativamente diferente e que correspondiam ao tipo não mutado ( $>30 \%$ células CD38+) e o tipo não mutado, embora alguns não mutados tivessem baixa expressão deste antígeno. Estes autores verificaram que o perfil de expressão do CD38 permanece constante ao longo da doença, o que não foi confirmado em outros trabalhos. Dados mais recentes de perfil de expressão gênica demonstram, porém, que se trata de duas formas variantes originárias da mesma célula-tronco, e não de duas doenças como se tem questionado. ${ }^{8}$

Estudando-se concomitantemente os linfócitos T (CD4 e CD8) no sangue periférico, com o intuito inclusive de excluir linfoproliferações T, nota-se que eles freqüentemente estão aumentados, especialmente os CD3 / CD8, o que pode expressar um mecanismo de reação do hospedeiro contra o tumor. ${ }^{9}$ Nota-se uma correlação inversa, especialmente dos CD3/CD8 com o estádio da doença.

\section{Diagnóstico diferencial}

Os principais diagnósticos diferenciais da LLC estão na tabela 1 . Vê-se que, com a morfologia do sangue periférico e um painel pequeno de anticorpos, pode-se facilmente fazer o diagnóstico de LLC. Para confirmar os principais diagnósticos diferenciais, poucos anticorpos a mais são necessários. A histologia de medula óssea é importante para o diagnóstico diferencial apenas do linfoma linfoplasmocítico CD5+. Este exame apresenta também subsídios diagnósticos importantes no linfoma esplênico e da tricoleucemia.

Se o caso ainda permanecer inconclusivo, pode-se realizar exame histológico de linfonodos.

O diagnóstico diferencial mais difícil e controverso é o do linfoma linfoplasmocítico leucemizado. Este tipo de linfoma é razoavelmente freqüente no nosso meio. Acome- 
te predominantemente medula óssea e baço. No sangue periférico podemos ter pancitopenia, mas também linfocitose. A morfologia das células neoplásicas circulantes não é diagnóstica por si só. Freqüentemente o paciente tem um pico monoclonal de imunoglobulinas (não só $\mathrm{IgM}$ ), ou anemia hemolítica auto-imune. Num estudo recente, todos os casos foram positivos para CD19, CD20 e CD52 à citometria de fluxo. CD79b foi positivo em 85\%, CD23 em $61 \%$ dos casos, CD38 em 48\% dos casos e apenas 5\% apresentaram expressão de CD5. ${ }^{4}$ Mas outros autores referem que este antígeno pode ser expresso em até $20 \%$ dos casos. $^{3}$ A histologia de medula óssea é característica: geralmente intersticial, acompanhado de intensa neoformação de vasos e fibrose.

\section{Abstract}

The diagnosis of CLL is based on the finding of peripheral lymphocytosis of over 5 (or 10) $\times 10^{9} / L$ presenting the CD19, CD5, CD23 phenotype and a weak monoclonal expression of membrane immunoglobulins. The CD38 expression is observed in half of the cases and is correlated with the unmutated status of the Ig V gene. Bone marrow biopsy should only be performed before starting treatment or if necessary for the differential diagnosis with other low-grade lymphomas. This differential diagnosis is based on the morphology of circulating lymphocytes, their immunophenotypes and pattern of bone marrow infiltration. Rev. bras. hematol. hemoter. 2005;27(4):233-235.

Key words: Chronic lymphocytic leukemia; diagnosis; phenotype; lymphoproliferative syndromes.

\section{Referências Bibliográficas}

1. Müller-Hermelink HK, Catovsky D, Montserrat E, Harris NL. Chronic lymphocytic leukaemia / small lymphocytic lymphoma - in: WHO Classification of Tumours; Tumours of Haematopoietic and Lymphoid Tissues. Jaffe ES, Harris NL, Stein H, Vardiman JW. Eds. IARC Press 2001;127-130

2. Gonzalez H, Maloum K, Remy F et al. Cleaved lymphocytes in chronic lymphocytic leukemia: a detailed retrospective analysis of diagnostic features. Leukemia \& Lymphoma 2002;43:555-564.

3. Owen RG, Barrans SL, Richards SJ et al. Waldenström macroglobulinemia: development of diagnostic criteria and identification of prognostic factors. Am J Clin Pathol 2001;116:420-428.

4. Konoplev S, Medeiros LJ, Bueso-Ramos CE et al. Immunophenotypic profile of lymphoplasmacytic lymphoma/Waldenström macroglobulinemia. Am J Clin Pathol 2005;124:414-420.

5. Shanafelt TD, Call TG. Current approach to diagnosis and management of chronic lymphocytic leukemia. Mayo Clinic Proceeding 2004; 79 : 388-398.

6. Babusikova O, Stevulova L. Analysis of surface and cytoplasmic immunoglobulin light/heavy chains by flow cytometry using a lysedwhole-blood technique: implications for the differential diagnosis of Bcell malignancies. Neoplasma 2004;51:422-430.

7. Damle RN, Wasil T, Fais F et al. Ig V gene mutation status and CD38 expression as novel prognostic indicators in chronic lymphocytic leukemia. Blood 1999;14:1.840-1.847.
8. Margalit O, Somech R, Amariglio N et al. Microarray-based gene expression profiling of hematologic malignancies: basic concepts and clinical applications. Blood Reviews 2005, 19: 223-234.

9. Oliveira GB, Pereira FG, Metze K, et al. Spontaneous apoptosis in chronic lymphocytic leukemia and its relationship to clinical and cell kinetic parameters. Cytometry 2001; 46: 329-335.

Avaliação: Carlos Sergio Chiattone

(publicado após acordo do Editor)

Conflito de interesse: Artigo derivado do II Encontro Brasileiro de

Consenso da LLC

Recebido: $13 / 10 / 2005$

Aceito: 30/10/2005 